\title{
Madame du Deffand, "salonnière" e impulsora de la sociedad intelectual y mundana del siglo XVIII. Traducción del retrato en verso de De Fos
}

\author{
(Madame du Deffand, "Salonnière" and Driving Force of the \\ $18^{\text {th }}$ Century Intellectual Society. Translation of the Portrait by De Fos)
}

Cristina Huertas Abril Universidad de Córdoba

Fecha de recepción: 11 de febrero de 2011

Fecha de aceptación: 14 de marzo de 2011

Resumen: La producción literaria femenina del siglo XVIIII ha sido menos estudiada y, por tanto, menos difundida que la de los siglos posteriores. En este siglo, periodo clave en la construcción cultural moderna de los países de la Europa occidental y en el desarrollo de las relaciones internacionales se encuentra el destacado Salón Literario de madame du Deffand. El presente trabajo pretende resaltar la importancia de esta destacada "salonnière". Para ello, abordamos su figura desde una perspectiva histórico-literaria y, posteriormente, realizamos la traducción al español del interesante retrato en verso escrito por De Fos sobre la marquesa.

Palabras clave: Madame du Deffand. Traducción poética. Siglo XVIII. Traducción literaria.

Abstract: Women's literature written in the $18^{\text {th }}$ century has been less studied and, as a consequence less disseminated, that the works of the following centuries. Moreover, the $18^{\text {th }}$ century, which is a crucial period in the development of Western Europe, bears witness of Mme du Deffand's salon littéraire. This paper aims to revalue the importance of Marie de Vichy-Chamrond. Firstly, we offer a study on her character from a historical and literary perspective, and secondly we complement the approach to the "salonnière" with the translation into Spanish of the interesting portrait written by De Fos about Mme du Deffand.

Key words: Madame du Deffand. Poetic Translation. $18^{\text {th }}$ Century. Literary Translation.
INTRODUCCIÓN
El valor literario de la escritura de madame du Deffand, clara y natural, se encuentra respaldado por Sainte-Beuve, uno de los mejores críticos de su generación y especialista consumado en esbozar "retratos" de los escritores que analiza. Este autor afirma (en Du Deffand, 1994:30): "Elle est, avec Voltaire, dans la prose, le classique le plus pur de cette époque, sans même en excepter aucun des grands écrivains"; esto va unido al 
carácter de Marie de Vichy, que queda reflejado en el autorretrato que escribe en 1728 y que recoge Lewis (1939: 48s):

Mme du Deffand paraît difficile à définir, le grand naturel qui constitue le fond de son caractère la laisse voir si différent d'elle-même d'un jour à l'autre que, quand on croit l'avoir attrapée telle qu'elle este, on la trouve l'instant d'après sous une forme différente. Tous les hommes ne seraient-ils pas de même s'ils se montraient tels qu'ils sont; mais, pour acquérir de la considération, ils entreprennent pour ainsi dire de jouer certains rôles auxquels ils sacrifient souvent leurs plaisirs, leurs opinions, et qu'ils soutiennent toujours aux dépens de la vérité.

El presente autorretrato está escrito por una mujer de unos treinta y dos años que busca cambiar su situación en la escena social, destacar la verdad de su persona, pues pertenece a una generación que evoca frecuentemente a la "vérité", frente a su discutible reputación y un fracaso matrimonial, por lo que siente que debe justificar de algún modo su comportamiento. Además de la necesidad de mejorar su imagen y, fundamentalmente, su prestigio social, sobresale en estas líneas la personalidad de una dama con una gran inestabilidad emocional pero, a su vez, de un gran talento para la escritura epistolar.

\section{MADAME DU DEFFAND, "SALONNIÈRE" Y EPISTOLÓGRAFA}

A pesar de que las líneas que siguen los trabajos sobre literatura francesa desde hace ya unas décadas, en su mayoría, no son proclives a dedicar mucha importancia a los aspectos biográficos, en el caso de madame du Deffand la relación entre su vida y su correspondencia es tan estrecha que se podría incluso considerar como un todo, pues su obra se comprendería de manera equivocada de no conocerse bien los datos correspondientes a su vida, así como algunos acontecimientos destacados de la época en los que ella participa, debido a su gran implicación tanto en la corte francesa como en la élite intelectual franco-británica. Así, la opción que se nos presenta más válida en este caso es la de tratar la biografía de la epistológrafa con aquellos personajes con los que se relacionará y que influirán en su vida y con los que mantendrá su ingeniosa correspondencia.

Se puede afirmar que Marie de Vichy-Champrond, pese a la ausencia de documentos concretos, nace el 25 de septiembre de $1696^{1}$ probablemente en el castillo de Champrond, propiedad de su familia y situado entre Mâcon y Vichy, en Ligny-en-Brionnais. Los Vichy poseen una

\footnotetext{
${ }^{1}$ Numerosos historiadores, e incluso biógrafos, consideran que nace en el año 1697, pero sus propias confidencias, los comentarios de Walpole y las publicaciones tras su muerte parecen confirmar que realmente nació en 1696.
} 
fortuna bastante mediocre, pero la familia tiene un gran estatus social debido a que sus antepasados se remontan a los primeros cruzados y pertenecen a la nobleza del mismo territorio desde el siglo XIV. Los Vichy cuentan con varios sirvientes y la educación de sus hijos (Gaspard, Nicolas, Marie y Anne) es acorde con su posición social. Así, Marie y Anne reciben su educación en el refinado convento de la Madeleine du Traisnel, en París, propiedad de una comunidad de benedictinas. Marie de Vichy aprende lo esencial de la enseñanza de los conventos de la época: el ton y las manières du monde, los dos aspectos que realmente importan en la educación de las jóvenes nacidas en las altas esferas de la época. Como afirma Murat (2003: 16s):

\begin{abstract}
L'instruction proprement dite consiste à inculquer des rudiments d'orthographe, de musique, d'arts ménagers... La femme savante est inutile et même indésirable. Les jeunes mariées lancées dans le monde vont parfaire leur éducation par la conversation dans les salons, les lectures personnelles, l'écoute des textes classiques au cours des représentations théâtrales.
\end{abstract}

En verdad la educación femenina parece depender en esa época de una formación a medias, sin método, y aunque muchas mujeres se contentaran con eso, Marie de Vichy sufrirá profundamente, pues para ella, el "ennui", junto con la incapacidad para creer, es una de las consecuencias más nefastas de la ignorancia. En cualquier caso, el programa de enseñanza del convento del Traisnel comprende una instrucción religiosa, ante la que la joven Marie ya se muestra completamente reacia ${ }^{2}$.

En torno a 1714, con dieciocho años, Marie sale del convento y regresa a la casa de su padre en Champrond, aunque por poco tiempo, pues no puede escapar a las alternativas impuestas a las muchachas en su época: el matrimonio o el convento. Así, en 1718, y según las costumbres, su matrimonio está decidido: el elegido es Jean-Baptiste Jacques, marqués du Deffand de La Lande, sobrino nieto de Nicolas Brûlart y, por tanto, primo de Marie. El 11 de junio de 1718 firman el contrato en el hôtel de Choiseul de la rue Royale en presencia de personalidades destacadas, pero con la ausencia del conde de Vichy, que prefiere permanecer en Champrond. Cuando obtienen la dispensación de los lazos de consanguineidad, celebran su enlace. Lescure, uno de los biógrafos más destacados de madame du Deffand, describirá el momento de su matrimonio de la siguiente forma, como recoge Craveri (2005: 19):

\footnotetext{
${ }^{2}$ El escepticismo religioso, que surge durante su infancia, siempre será una constante en la vida de la Marquesa du Deffand.
} 


\begin{abstract}
El 2 de agosto de 1718, en el momento en que la reacción de desenfreno es más acusada, (...) en el momento en que el matrimonio no es sino una formalidad y la fidelidad es ridícula, mademoiselle de Vichy se vio arrojada, gracias a la solicitud de una familia impaciente por darle un responsable legal, y tranquilizada además por las conveniencias, que todo lo garantizan, salvo la felicidad, a los brazos de un marido al cual ni siquiera conocía antes del día en que pasó a pertenecerle para siempre.
\end{abstract}

El matrimonio, sin embargo, se le presenta como fuente de numerosas ventajas pues, además de marcar el inicio de la vida social, le supone también la liberación de la amenaza de una vida en el campo o en el convento, así como la emancipación de su padre. Con todo, el marqués du Deffand tiene aspiraciones de carácter familiar, pues suele describírsele como un hombre simple y recto, amante de la vida familiar, de las provincias y de la caza. Madame du Deffand se aburre infinitamente con su marido, pues su curiosidad está intacta, y desea descubrir y experimentar el mundo, o más concretamente la sociedad parisina, a lo cual se une el hecho de que y la Regencia muestra posibles todas las aspiraciones de la marquesa. De hecho, la carrera libertina de Marie comienza de un modo considerablemente rápido, pues su primer amante será el Regente. Tan solo serán dos semanas, tiempo que no obstante se considera bastante prolongado debido a los numerosos affaires que se le conocen al duque de Orléans, pero el fin de esta unión carnal no acaba la relación entre el Regente y la marquesa, que quedan unidos por una gran complicidad. Por consiguiente, el entendimiento entre los esposos resulta imposible, no solo debido a sus distintos gustos y personalidades, sino también por su carácter e inteligencia. El Marqués nunca llegará a aceptar la inquietud de Marie y sus ansias de huir del aburrimiento, de forma que recurrirán, cuando la situación se vuelve irremisible, a una separación de hecho poniendo fin a su vida en común en 1722. Durante los últimos meses de ese mismo año se producen numerosos cambios en la Regencia, de forma que madame du Deffand buscará diversificar su universo. Luis XV se encuentra en Versalles desde el mes de junio, mientras que el Regente persigue el retorno a las prácticas políticas del difunto "Roi Soleil", pues la opinión pública comienza a tomar consciencia de la fragilidad de las novedades.

Las amistades que años más tarde constituirán el núcleo de su Salón y que representarán el aspecto más continuo y sólido de su vida, se establecen ya durante los años de la Regencia. A los Ferriol, Tencin, etc., se unirán los amigos extranjeros que vendrán a traer los aires cosmopolitas que comienzan a expandirse por Europa. Entre estos últimos se encuentra Lord Bolingbroke, hombre de letras y político inglés, que tiene la desgracia de ser tory en un país dominado por los whigs. Exiliado de Inglaterra y 
refugiado en Francia, se reúne frecuentemente con madame du Deffand a partir de 1721. Su amistad se entabla con fuerza en cuanto se conocen: siempre serán amigos, pues comparten numerosas ideas así como sienten nostalgia de la rigidez existente en el siglo de Luis XIV.

El duque de Orléans, primer ministro del joven rey, muere de una apoplejía el 2 de diciembre de 1723. Luis XV aún tiene solo trece años, de forma que el duque de Bourbon, superintendente de su educación y nieto natural de Luis XIV, exige el puesto de ministro principal, a lo que accede el joven rey con la aprobación del Cardenal de Fleury. Francia y el mundo parisino, con esta medida, parecen vivir bajo una especie de Regencia prolongada. Aun así, su gusto por la corte o incluso su realismo, llevan a la marquesa Du Deffand a cultivar la amistad con madame de Prie, amante del nuevo primer ministro.

No obstante, el 11 de junio de 1726 marca la desgracia del duque de Bourbon y de la marquesa de Prie: ambos creen que pueden apartar del poder al ya anciano cardenal de Fleury, esperanzados en contar con el apoyo de la reina. Sin embargo, el Cardenal, convertido en ministro principal, ordena al rey el exilio del duque de Bourbon a sus tierras de Chantilly y a madame de Prie a las suyas de Courbépine, en Normandía, adonde la acompaña madame du Deffand ${ }^{3}$. La sociedad se somete al bon ton y visitan a ambos, de forma que fiestas, conciertos y comedias se suceden en Courbépine. Sin embargo, el destierro arrastra a la joven a la muerte y un año después, en 1727, muere en condiciones terribles y misteriosas. Este final trágico de madame de Prie, sin duda, supone claramente una fuente de meditaciones para la marquesa preocupada ya entonces por el comienzo de la madurez y su futuro realmente incierto. Se acaba una etapa en la historia de Francia y Marie de Vichy-Chamrond comprende que también se acaba un período de su vida. La Regencia y su época han marcado de forma imborrable su carácter, su idea de la representación social y sus gustos, que quedarán más adelante reflejados en su Salón, un tono aristocrático que evocará el mundo parisino de su juventud.

En su búsqueda por determinar su situación en el plano social y buscar la verdad sobre sí misma, a mediados de 1728 madame du Deffand decide volver con su marido, aunque su reconciliación no durará mucho. Su abuela, la duquesa de Choiseul, acaba de morir y su testamento abatirá a su descendencia, que se encuentra casi completamente desheredada. Para

${ }^{3}$ Como afirma Craveri (2005: 23): "Los motivos que inducen a madame du Deffand a acompañar al destierro a la favorita en desgracia no son solo los sugeridos por el cronista [su semejanza en 'belleza, galantería y maldad']. Probablemente el origen de este gesto de solidaridad esté en el orgullo de no retractarse, en cierta afición a los desafíos (una constante en su carácter) y, por qué no, en un vínculo real con madame de Prie". 
Marie de Vichy, que vive con lo estrictamente necesario en una época en la que el lujo es frecuentemente ostentoso, es una noticia realmente negativa, Este puede ser entonces uno de los motivos que la llevan a regresar con su marido quien, impaciente, desea retomar su vida en común de inmediato. En la correspondencia de Aissé, como recoge Murat (2003:37s), sin embargo, se afirma lo siguiente:

C'était la plus belle amitié du monde pendant six semaines: au bout de ce temps-là, elle s'est ennuyée de cette vie et a repris pour son mari une aversion outrée; et, sans lui faire de brusqueries, elle avait un air si désespéré et si triste qu'il a pris le parti d'aller chez son père. (...) La fin de cette misérable conduite, c'est qu'elle ne peut vivre avec personne.

Madame du Deffand se encuentra por tanto muy triste, en medio de una sociedad muy bien organizada en torno a sus distintas clases y a los distintos rangos de las personas que la componen. Asimismo, se van introduciendo nuevas ideas en las élites sociales, entre las que destacaría el bonheur, que se puede definir como una gran negación, pues consiste en negarse a sufrir, a carecer de bienes materiales, a tener una mala salud... En cualquier caso, el papel de Marie de Vichy en sociedad quedará marcado por la llamada Cour de Sceaux en su segunda etapa ${ }^{4}$, le deuxième Sceaux, que comienza en 1720, año en el que probablemente la marquesa Du Deffand, veinte años más joven que la anfitriona, conocerá allí al presidente Hénault, cuando él aún es amante de la mariscala de Estrées. Este período, en cierto sentido, es menos brillante y festivo que el primero, pero muy atrayente, pues la duquesa du Maine reúne en Sceaux a las élites intelectuales, parlamentarias, aristocráticas y eclesiásticas. Como señala Murat (2003: 45):

\footnotetext{
${ }^{4}$ El duque Du Maine, hijo legitimado de Luis XIV y de madame de Montespan, es un hombre tímido, poco dotado para las armas, pero cuenta con un gran ingenio y una gran fe. Sin embargo, parece eclipsado por la personalidad extremadamente viva y dominante de su esposa, que decide a principios de siglo hacer revivir las horas mágicas de la juventud de Versalles, en los bellos terrenos de Sceaux, comprados al hijo de Colbert. De esta forma, las conocidas como Les Nuits de Sceaux quedan recogidas en todas las memorias de la época. El duque, que mantiene una gran relación con su madre que lo había criado, tiene el rango de príncipe de sangre con derechos de sucesión a la Corona. La muerte de Luis XIV, junto con la casación de su testamento, le hace desechar todas sus esperanzas para ser Rey de Francia. Así, la duquesa du Maine, molesta por el hecho de que su marido sea bastardo, arrastra a su marido a un complot contra el Regente, a favor de Felipe V, rey de España. En 1718, la famosa conspiración de Cellamare los lleva a los dos a prisión, el Duque durante un año y la Duquesa durante quince meses, de forma que termina el conocido como première Sceaux.
} 
Parmi les piliers de sa cour à cette époque, l'on y rencontre Hénault, son "président ordinaire", le marquis de Sainte-Aulaire, charmant poète de quatre-vingt-sept ans qu'elle nomme son "berger", le premier président de Mesmes, le cardinal de Polignac, "le plus beau parleur de son temps", selon Hénault, Fontenelle alors âgé de soixante-treize ans, la gloire littéraire de Sceaux... Parmi les dames l'on y voit Mme de Charost, la présidente Dreuillet qui compose des chansons tout au long des jours, Mme d'Estaing, la duchesse de Saint-Pierre, la duchesse d'Estrées... Mme de Lambert, la devancière des salons parisiens qui vont apparaître dans les décennies à venir, est alors très âgée et infirme

Marie de Vichy vivirá en Sceaux durante casi veinte años. No puede negarse que a madame du Deffand le impresiona el prestigio de madame du Maine, junto con la supervivencia de una corte que sigue las líneas de la del Rey Sol. La duquesa es una imagen viva del siglo XVII en el que el ocio permite, e incluso impone, las bromas en todas las disciplinas. Así, madame du Deffand, que no soporta la gravedad de los filósofos que surgirán en el XVIII, los considerará descorteses, prefiriendo ver y participar en la frivolidad de Sceaux, donde los sucesos del día se cuentan en forma de canciones. Otro divertimento que destacará la presencia de Marie de Vichy será, además de la improvisación literaria, la realización de retratos, moda que había comenzado en la época de Luis XIV. El arte del retrato consiste en penetrar en los rasgos más característicos de las personas: sin gravedad ni suficiencia, madame du Deffand desmenuza los aspectos físicos y mentales de los asistentes a Sceaux con un gran éxito.

Marie de Vichy también coincide con el presidente Hénault en la corte de madame de Prie junto con Voltaire, amigo de ambos. A menudo se encuentran en Sceaux. Como afirma Craveri (2005: 27):

En los comienzos de su relación con madame du Deffand el presidente Hénault tiene unos cuarenta y tres años, se ha quedado viudo hace poco, es rico, culto y brillante. El deseo de agradar es en él una verdadera pasión y se entrega a ella metódicamente.

Así se anuncia una nueva etapa en la vida de madame du Deffand, pues entre ella y el presidente Hénault nace una relación fundamentalmente social, debido a que ambos tienen una necesidad vital, absoluta: la vida en sociedad. Marie de Vichy encuentra en él la forma perfecta para seguir perteneciendo al escenario mundano en el que puede representar su papel y mostrar su ingenio, desligándose de esta forma de su pasado, mientras que el presidente Hénault parece quedar deslumbrado por el brillante deseo y predestinación de la marquesa a las relaciones mundanas. Él es quien introduce a su amante y amiga en los círculos que conformarán, ya en su 
madurez, la celebridad de su Salón. El presidente la introduce en uno de los círculos más brillantes de París, el de Brancas, en el que la idea de clan da a este tipo de sociedad la apariencia de una especie de nebulosa tribal.

Asimismo, en los Salons de Brancas, madame du Deffand conocerá a Pont-de-Veyle, a los duques de Châtel, a los Maurepas, a D'Ussé (amante de madame de Rochefort) y a los Flamarens, entre otros. Poco a poco, va ampliando su red de amistades y conocidos, puesto que todas las energías de Marie de Vichy están orientadas a encontrar un lugar propio en la elegante escena social que ocupa su vida. Detesta las conversations philosophiques del Salón de madame de Tencin, al igual que el tono religioso que tienen otros Salones durante este período, mientras que le atrae el savoir-faire aristocrático que mantiene Brancas. Poco después de conocer a Pont-de-Veyle conocerá a Formon, otro conocido muy apreciado de Voltaire, que se convierte en su amigo más cercano.

Tras un viaje a Forges con una finalidad terapéutica, Marie de VichyChamrond vuelve a encontrarse con París y el presidente, así como con Sceaux y la duquesa du Maine. Su relación con Hénault pasa a ser una amistad cómplice y apenas sin ilusión de carácter sexual. Con todo, y pese a que Sceaux suponga la entrada definitiva y la metamorfosis de madame du Deffand en el aspecto social, considera que se ha visto en una especie de esclavitud prolongada y rutinaria a la sombra de la duquesa du Maine, debido a las numerosas ventajas y protección de las que ha gozado, y comienza a alejarse en el año 1747. Así, la aparentemente interminable estancia en Sceaux no le impide preparar su independencia parisina y apropiarse de una parcela propia en el territorio mundano. Su equilibrio vital depende ahora de conquistar su propia independencia, así como de crear su propio Salón, para lo que siempre contará con la ayuda incondicional del presidente Hénault. Madame du Deffand desea, por tanto, establecer un Salón en la sociedad parisina, tras haber realizado numerosos "ensayos" en un pequeño piso de la rue de Beaune y después cuando pasa un tiempo en 1740 con su hermano el abate de Champrond y tesorero de la SainteChapelle, durante el tiempo que ha conseguido "robar" a la duquesa du Maine al ausentarse de Sceaux.

Madame du Deffand cuenta con un presupuesto modesto que le impide comprarse un apartamento en el elegante quartier du Marais, en el que hay una homogeneidad social que la seduce profundamente, pues todos los vecinos pertenecen a la élite. Sin embargo, son numerosas las comunidades religiosas de la capital que alquilan apartamentos en edificios anexos pero distintos a los del propio convento. Es una solución muy utilizada principalmente para mujeres que viven solas, están separadas 0 viudas, pues les proporciona independencia en un marco social respetable. En la rue Saint-Dominique, se instala la comunidad de las Filles de Saint- 
Joseph a mediados del siglo XVII y en 1747 madame du Deffand se trasladará, viviendo allí durante más de treinta años, hasta su muerte, en la que fuera residencia de madame de Montespan ${ }^{5}$, que cuenta con un acceso independiente a través de un patio que da a la rue Saint-Dominique. Como consecuencia, la fortuna de madame du Deffand aumenta de forma notable, de manera que le asegura una independencia y un tren de vida que, sin ser demasiado ostentoso, no deja de ser confortable. Los tres primeros años en Saint-Joseph, sin embargo, fueron precarios, pese a la ayuda discreta y seguramente generosa del presidente Hénault, pero la verdadera apertura de su Salón comienza tras la muerte de monsieur du Deffand. El Salón de madame du Deffand se convierte así en uno de los centros mundanos más importantes de la capital, éxito que tiene lugar en una época muy favorable al florecimiento de los Salones parisinos y al dominio cultural de París, pues la capital francesa en esta época es centro de poderes mundanos, literarios y políticos, que se interrelacionan, se dispersan y crecen.

Los Salones de madame du Deffand y de madame Geoffrin son los más importantes, de forma que comenzará una fuerte rivalidad entre ellas. El Salón de madame Geoffrin representa con gran éxito el poder que tienen las salonnières prestigiosas de mitad del siglo XVIII al dirigir una parte importante de la vida intelectual francesa. Sin embargo, madame du Deffand no la aprecia, pese a que tengan invitados en común, pues madame Geoffrin aparece como la antítesis de la marquesa; a la frialdad, ironía y gran ingenio de madame du Deffand se contraponen por completo la fineza natural, poca imaginación y el ingenio ordenado y tranquilo de madame Geoffrin.

Con todo, a mediados del siglo XVIII, cuando el Salón de madame du Deffand cuenta con un éxito más que notable en la sociedad parisina y es visitado por todos los extranjeros que viajan a la capital francesa, la marquesa, que acaba de cumplir los cincuenta años, atraviesa una de sus peores etapas. Al ennui y los vapores ${ }^{6}$ que la llevan acompañando toda su

\footnotetext{
${ }^{5}$ Protectora del convento, amante de Luis XIV y madre del Duque du Maine. Se retirará a Saint-Joseph para alejarse de las intrigas versallescas.

${ }^{6} \mathrm{Si}$ consultamos la entrada ,vapor' en el DRAE, en su sexta acepción se define como "Accesos histéricos o hipocondríacos, atribuidos por los antiguos a ciertos vapores que suponían nacidos de la matriz o de los hipocondrios y que subían hasta la cabeza". Asimismo, resulta realmente ilustrativa la siguiente observación de Craveri (2005: 374): "El responsable del desarrollo de la teoría de los vapores a partir de las consideraciones de Galeno sobre la fermentación de las orinas fue, al parecer, Jean Fernel (1479-1558), profesor de la Escuela de Medicina de París y autor de Universa Medicina (1567). En Fernel, el término, 'vapor' tiene un sentido literal y clínico. Los diferentes órganos pueden estar, sucesivamente o a la vez, infectados por emanaciones pútridas que producen síntomas específicos de creciente gravedad: 'Cuando ese vapor ha llegado al cerebro, o bien causa lo que se llama furor uterino, con logorrea, cólera e inquietud; o bien excita otras formas de locura, repletas de temores y horror; a veces causa un profundo sopor, que hace caer sin sentido a las personas' (Pathologie de Jean Fernel, París
} 
vida, se le suma ahora una sombra que le ocasiona a una crisis moral y psicológica especialmente grave: comienza a perder visión. Su ceguera aumenta progresivamente y al miedo a perder la independencia que tanto le ha costado lograr se une el temor al rechazo de la sociedad: el pánico a ser abandonada la obsesiona y no duda en identificar a su peor enemigo, constantemente al acecho, con el aburrimiento. Como señala Craveri (2005: 106):

\begin{abstract}
Vapores, aburrimiento, melancolía, son síntomas de un mal existencial que a partir de mediados del XVIII cosecha un número creciente de víctimas y se impone también como nuevo modo de ser, expresión de una sensibilidad más compleja, que nutre gran parte de la literatura prerromántica y a su vez bebe en ella. Pese a constituir uno de los primeros y más clamorosos casos de esta epidemia, madame du Deffand no comparte con sus contemporáneos el narcisismo del sufrimiento, la complacencia en su propia sensiblerie, la sensación de la excepcionalidad de su destino.
\end{abstract}

Por este motivo acude con mayor frecuencia a Sceaux, lugar que le ha proporcionado seguridad durante numerosos años. Mas el avance de su enfermedad aumenta también sus perjuicios hacia los cambios mundanos e intelectuales que tienen lugar en ese momento. Estas nuevas luces no la deslumbrarán, sino que más bien la llevarán a encerrarse en su propio mundo. Durante este período de crisis, madame du Deffand se confía, no sin cierto abandono, a un genovés al que conoce desde hacía poco tiempo: Jean-Louis Saladin. Sus verdaderos amigos se preocupan por el delicado estado de salud que tiene madame du Deffand; por ejemplo, Montesquieu no duda en aconsejarla y en tratar de ayudarla, pues conoce los peligrosos estragos que el tedio, el conocido ennui, puede causar en la salud física y moral de la marquesa. Voltaire también estará a su lado y le dedicará años después los siguientes versos:

\footnotetext{
Oui, je perds les deux yeux; vous les avez perdus

O sage Du Deffand. Est-ce une grande perte?

Du moins nous ne reverrons plus

Les sots dont la terre est couverte.
}

1661, pág. 498). Solo con Joseph Raulin, en la segunda mitad del XVIII, se difunde el uso metafórico y eufemista del término 'vapores'. En la segunda mitad del siglo, los vapores se concretan como afecciones típicas de las mujeres. 'Los vapores se han puesto de moda entre las mujeres del mundo; Hunauld, autor de una Dissertation sur les vapeurs (1756) y Vaudermonde, autor de un Essai sur la manière de perfectionner l'espèce humaine (1756), opinan que ellas demuestran cierta complacencia en padecerlos. Así Hunauld establece una categoría particular de vapores que llama 'de moda', en los cuales 'entran al menos tantos misterios del corazón como disposiciones de los humores'”. 
Et puis tout est aveugle en cet humain séjour;

On ne va qu'à tâtons sur la terre et sur l'onde;

On a les yeux bouchés à la ville, à la cour;

Plutos, la Fortune et l'Amour

Sont trois aveugle-nés que gouvernent le monde. ${ }^{7}$

El terror de madame du Deffand a quedarse ciega amenaza su estilo de vida, pues no soporta la soledad y, para sorpresa y disgusto de sus amigos, anuncia su determinación a abandonar París para siempre, dejando en la capital francesa, además de a sus amigos y conocidos, su magnífico Salón. El 1 de mayo de 1752 Marie de Vichy decide reunirse con su hermano, el conde de Champrond, en el castillo familiar situado en Borgoña. Afronta ella entonces un largo viaje teniendo la esperanza de conseguir la calma, una vida más sana e intentar que disminuya su ceguera 0 , al menos, evitar que continúe agravándose. La acompaña en su viaje, además de su doncella personal, probablemente su secretario, pues su avanzada ceguera ya no le permite escribir cartas de su puño y letra. De hecho, desde el mes de marzo de ese mismo año ya contaba con la ayuda de Wiart, a quien le dicta sus cartas y quien le servirá con una gran devoción, discreta pero sincera, hasta su muerte.

Con todo, había algo imposible para esta mujer: nunca podría integrarse totalmente en la vida de provincia, puesto que anhela la forma de vida de París. Por otra parte, no le interesa la naturaleza, por lo que años más tarde reconocerá que era poco sensible a los campos que rodeaban Champrond. La llegada de la marquesa al castillo de Champrond supone un cambio para la vida de su sobrina, Julie de Lespinasse ${ }^{8}$, pues madame du Deffand pronto percibe el carácter de la joven y se queda prendada de ella.

7 Sí, pierdo los dos ojos; vos los habéis perdido

Oh, Du Deffand sensata ¿Es esto una gran pérdida?

Al menos ya nunca veremos

a los necios que pueblan esta tierra.

Además todo es ciego en esta estancia humana

no se va más que a tientas en la tierra y el agua, con los ojos cerrados a la ciudad y la corte,

Pluto, la Suerte y el Amor

son tres nacidos ciegos que gobiernan el mundo.

${ }^{8}$ Su presencia supone una gran traba para la familia pues, aunque no se revelará públicamente hasta pasado mucho tiempo, Mlle Lespinasse es hija ilegítima del Conde de Champrond y de la Condesa D'Albon. Julie nace el 9 de noviembre de 1732 y se la declara hija de Claude de Lespinasse y de Julie Navarre (ambos son personajes inventados y, por tanto, inexistentes). Con todo, la Condesa d'Albon amaba realmente a su hija, de forma que ella crecerá con su verdadera madre. La vida de Julie, sin embargo, se tambalea con la muerte en 1748 de Mme d'Albon, pasando a ser acogida por Gaspard de Vichy, que es a la vez su padre y su cuñado, y por Diane d'Albon, hermanastra y madrastra. 
El impacto que se producen mutuamente, entre la fría cincuentona y la veinteañera que se mueve por impulsos, las marcará para siempre. Durante seis meses, la marquesa y Julie viven juntas en el castillo de Champrond, aisladas del mundo, insertas en la rutina de una vida familiar que realmente, aunque por motivos distintos, les es ajena. Sin duda, el hecho de que ambas se sientan fuera de esa vida general las acerca cada vez más. Asimismo, la idea de poder contar con una mujer joven, inteligente y agradable para que le ayude en su vida, marcada ya por la ceguera, hace que sus quejas y sus miedos hacia el futuro disminuyan. Madame du Deffand comienza a planear entonces la manera para atraer hacia ella a Julie: ella espera que la situación de inferioridad de su sobrina, pues la joven no tiene estatus social ni dinero, la anime a aceptar y seguirla a París.

La marquesa, que con la marcha de Julie ha perdido a una de sus mejores amigas en Champrond pero que aún no se siente preparada completamente para regresar a París, en diciembre partirá hacia Mâcon y Lyon con la excusa de ir a visitar a dos obispos amigos suyos. No obstante, resulta bastante evidente que su principal motivo es visitar a Julie de Lespinasse pues, aunque tiene la intención de volver a abrir su Salón, es completamente consciente de que su ceguera es irreversible. Una vez que la joven está decidida a trasladarse a París, ambas traman un importante complot, mediante una abundante correspondencia, para negociar con Gaspard de Vichy. Hacia finales de mayo de 1753, madame du Deffand regresa a París sin Julie, mas con el deseo y la esperanza de que se reunirá con ella en poco tiempo. Como brevemente resume Savater, en la introducción a la obra de Cobos (1988: 19):

Encantada por el talento natural y la discreción de la joven, la marquesa pensó convertirla en una útil lugarteniente de su generalato en el salón; para Julie, la gran dama de París era la posibilidad de huir a su vida humillante y sometida en la aburrida provincia.

Ya en París, la marquesa emprende sin más demora su labor para encumbrar a D'Alembert aunque ambos han de esperar casi un año con paciencia y perseverancia, pues tres nuevos elegidos, un aristócrata (Clermont) y dos escritores (Bougainville y Boissy) ocupan los tres sillones que habían quedado vacantes. El fallecimiento del obispo de Vence, Suiran, dejará libre otro, de manera que la marquesa du Deffand, apoyada por la duquesa d'Aiguillon y por madame Mirepoix, inicia su ofensiva. A pesar de los resentimientos de Hénault, debido a sus discrepancias con D'Alembert, el presidente aún es sensible a los deseos de su antigua amante, por lo que decide darle su apoyo al protegido de madame du Deffand. Su principal rival es el abate Boismont, respaldado por la duquesa de Chaulnes, pues se compite tanto por reafirmar el prestigio de los candidatos como el de sus 
protectores, pero finalmente, el 29 de noviembre de 1754, D'Alembert entra a formar parte del selecto grupo de la Academia Francesa, lo que supone un importante triunfo personal para la marquesa y para el prestigio de su Salón. Igualmente, marca una etapa fundamental en la expansión de la llustración, algo que algunos años más tarde lamentará la marquesa.

Marie de Vichy no se olvida de Julie de Lespinasse, pues nunca ha perdido la esperanza de poder llevársela consigo a París. Esta vez será Julie quien volverá a plantear su traslado, aceptando las condiciones que le impone madame du Deffand. Así, la marquesa consigue superar su otro reto: contar en su Salón con la presencia de mademoiselle de Lespinasse. A partir de entonces, la marquesa ya no estará sola al abrir las puertas de su Salón cada día, en torno a las seis de la tarde, y recibir a sus invitados. Julie de Lespinasse sale a recibir a los asistentes, de forma que los asiduos del Salón pronto se acostumbrarán a la presencia de esta joven a quien la marquesa ha presentado como "une jeune fille de ma province". Julie en un principio se instala en una vivienda situada debajo de las cocheras de las calesas aunque no tardará mucho en mudarse al entresuelo. Marie de Vichy, ya completamente ciega y prácticamente inválida por sí misma, comienza a aprender a adivinar la fisonomía de sus invitados tocándole sus caras con las manos. Julie, contrastando completamente con la pálida y menuda marquesa, es alta, esbelta y muy inquieta, posee unas cualidades sociales extraordinarias e innatas y, a diferencia de madame du Deffand, valora a sus invitados.

El presidente Hénault muestra a Julie de Lespinasse un sentimiento realmente paternal, y la joven pasa a ser para la marquesa un verdadero imán para devolver al Salón de Saint-Joseph a su antiguo amante. Sin duda, quien más atrae la atención de Julie en el Salón es D’Alembert y él también se sentirá cautivado por ella pues, como escribirá años después, tienen muchas cosas en común: los dos, hijos ilegítimos, han experimentado a lo largo de su vida el abandono y la injusticia, por lo que se sienten ligados a tener un destino juntos debido a su pasado paralelo.

Debido a la influencia, por tanto, que ejerce Julie en los invitados del Salón, en él comienza a hablarse, si bien en voz queda, de filosofía, republicanismo, reformas y constitucionalismo. Además de los asiduos provenientes de las altas esferas de la aristocracia, gens de lettres y los extranjeros ilustres, comienzan a asistir al Salón nuevos visitantes atraídos por la presencia de D'Alembert y de Julie de Lespinasse. A pesar del inicial entendimiento entre Julie y la marquesa, en 1764 se producirá la ruptura entre ambas, un episodio pintoresco y conocido en el panorama intelectual de la Francia dieciochesca y que será ocasionado, fundamentalmente, por D’Alembert. 
Madame du Deffand se percata de los sentimientos de su protegido por Julie, y lo que al principio considera como una garantía para que él siga visitando el Salón, pasará a ser con el tiempo resentimiento por parte de la marquesa y desprecio por parte de D'Alembert. Este, en un principio, se muestra prudente con madame du Deffand por respeto a mademoiselle de Lespinasse, pero con el estreno en 1760 de la obra satírica Les Philosophes de Charles Palissot, D'Alembert comienza una guerra fría con Marie de Vichy-Chamrond, de la que ella da pruebas de una mayor educación y elegancia a las de él. En respuesta a una carta de D'Alembert, en la que este tacha de "puta en funciones y ramera honoraria" a la marquesa, Voltaire le dice al philosophe que lo mejor que se puede hacer en un siglo "ridicule" es reírse de todo.

Julie, que en ese momento se encuentra entre dos aguas, intenta realizar un complejo y sutil papel mediador. Las dos mujeres están acostumbradas ya a vivir juntas y la vida del Salón les es fundamental, pues supone una fuente inagotable de debates, novedades y comentarios. En 1763 D'Alembert solicita a Federico de Prusia ir a Postdam, de manera que marcha a hacer un viaje que considera como peregrinación al centro del despotismo ilustrado. En este viaje se da cuenta de su gran cariño hacia Julie, a quien envía numerosas cartas de contenido privado y que no han sobrevivido al paso de los años, mientras que a madame du Deffand apenas la cita una sola vez en toda la correspondencia de este período. No obstante, una carta con fecha 28 de junio de 1763, escrita por D'Alembert desde Sans-Souci y dirigida a la marquesa, la lleva a equívoco, pues ella la considera como una vuelta a la "edad de oro" de su amistad, pero no hay nada más lejos de la realidad. Cuando D'Alembert regresa a París, asiste al Salón de madame du Deffand, aunque su actitud es fría y distante y toda su atención la dirige hacia Julie de Lespinasse. La marquesa se da cuenta de que su dama de compañía la ha sustituido y, además, le ha robado a quien más apreciaba: a su protégé. Una sensación de injusticia e ingratitud se adueña de la marquesa y la presencia de Julie le comienza a resultar cada vez más insoportable. Tan solo unos meses después del regreso de D’Alembert, la relación entre tía y sobrina llega a su fin. Julie se había acostumbrado a recibir a los invitados una o dos horas antes en su pequeña vivienda. Animada por D'Alembert, su petit ami, que cuenta ahora con un gran éxito y progreso en el mundo social y literario, lidera a los ingenios más importantes, entre los que destacan Turgot, Condorcet y Marmontel. La pequeña vivienda de Julie es conocida como el laboratoire de l'Encyclopédie entre los hermanos Goncourt, nombre que utilizarán para denominar el futuro Salón de mademoiselle de Lespinasse. En realidad, este es el único momento de autonomía del que goza Julie, para ella misma y para hablar con sus amigos. Tras esos minutos de conversación, todos 
suben por la pequeña escalera para reunirse con la anciana ciega y disimulan no haberse visto en los instantes previos. Sin embargo, cuando madame du Deffand la descubre, al igual que el disimulo de sus invitados, este hecho se convierte en la más clara evidencia de la traición de su sobrina. La marquesa estalla en cólera y la expulsa de la casa. Considerando que los amigos de Marie de Vichy también lo son de Julie de Lespinasse, y que ninguno está dispuesto a posicionarse contra ella, la primera considera que imponer una elección entre ella y su sobrina conllevaría la muerte de su Salón y, probablemente, de su vida social. Por este motivo, un conjunto de personas, entre los que sobresalen el presidente Hénault y madame de Luxembourg, le consiguen a Julie un alojamiento, muebles y una renta para que pueda vivir dignamente el resto de sus días. Esto supone el comienzo del Salón de madeimoselle de Lespinasse, que será durante varios años el centro de la vida intelectual parisina.

Poco después de haber expulsado a su sobrina, madame du Deffand arriesga su relación con D’Alembert y le da un ultimátum: que no vuelva a su Salón si vuelve a encontrarse con Julie de Lespinasse. Así, D’Alembert abandona para siempre el Salón de madame du Deffand, junto con todos sus amigos philosophes y el marqués de Ussé. El Salón de Marie de Vichy pasa a ser esencialmente aristocrático, aunque con algunos cambios, pues sus verdaderos amigos la ayudarán a seguir adelante y a mantenerlo. La década de los sesenta recoge los años fundamentales de la renovación de la cultura francesa, de la crisis de la política exterior y de la involución de la política interior, cambios a los que el Salón de madame du Deffand se mantiene completamente ajeno, al igual que los de madame de Luxembourg o del príncipe de Conti, que se quedan como santuarios del verdadero esprit français.

La ruptura con mademoiselle de Lespinasse supone que la marquesa atraviese uno de los momentos más oscuros de su vida. Madame de Aulan, que previendo la situación que se avecinaba se había trasladado en abril de 1764 a casa de su hermana, Marie de Vichy, será su dama de compañía hasta su muerte en 1769, cuando mademoiselle de Sanadon ocupará su lugar y también se esforzará para tratar de reemplazar la presencia de Julie. Mademoiselle de Sanadon, hija del padre Sanadon, jesuita y preceptor del Príncipe de Conti, y que es nombrada en las cartas de la marquesa como "la Sanadona", está encantada por ser la dama de compañía de madame du Deffand y porque se le permite asistir a las comidas de Saint-Joseph, donde se reúne la alta sociedad. Tras largas noches insomnes, la marquesa suele dormirse al alba. En la cama prolonga las conversaciones de su Salón dictando cartas a Wiart o utilizando una pequeña máquina que ella llama écritoire. Con todo, sobre las cuatro de la tarde se la instala cerca de la 
chimenea de su habitación en un sillón conocido como tonneau debido a su alto respaldo que la protege de las corrientes de la habitación. Va siempre vestida de forma sobria y lleva una especie de cofia con bordados. Los asistentes comienzan a llegar en torno a las seis de la tarde y a las nueve de la noche el Salón de madame du Deffand se encuentra lleno de invitados. Dos veces a la semana, los miércoles y los domingos, la marquesa ofrece cenas para catorce, o incluso dieciséis, comensales. La inteligencia de madame du Deffand sigue asombrando y asustando a partes iguales, debido a la autonomía de sus críticas y también por la campaña que están haciendo contra ella Julie de Lespinasse, D'Alembert y madame Geoffrin.

Sin embargo, y pese a ser considerada la bête noirse des philosophes, bien es cierto que mantiene una gran amistad con Voltaire desde hace muchísimos años. Aunque desde 1750 Voltaire ya ni siquiera vive en París, sigue estando muy presente en la sociedad francesa, pues desde tierras suizas siguen llegando panfletos, novelas, epístolas, poemas, tragedias, cuentos, etc. impresos en Suiza, Holanda e Inglaterra. Sceaux es el lugar donde madame du Deffand y Voltaire consolidan su amistad, pues allí pasan juntos largas temporadas y sus afinidades son cada vez más evidentes. La correspondencia entre ambos, aunque interrumpida durante algunos períodos concretos, es muestra clara de su buena relación así como de sus esfuerzos para sorprender al otro con su lectura. Como afirma Craveri (2005: 187):

La correspondencia entre madame du Deffand y Voltaire es una competición entre los virtuosos, en la cual la paciencia por brillar va acompañada, empero, por la conciencia de que la excelencia del antagonista es indispensable para realzar plenamente la propia.

Con el transcurso de los años, el argumento de los buenos tiempos pasados, de la fidelidad al buen gusto y la educación son tres constantes en las cartas de estos dos epistológrafos a quienes Sainte-Beauve eleva a la altura de dos genios del siglo XVIII francés. Asimismo, la marquesa cuenta con otros dos apoyos fundamentales: el presidente Hénault y Pont-deVeyle.

En 1763, el fin de la Guerra de los Siete Años anuncia la supremacía de Inglaterra en los planos político y militar. La anglomanía cobra una mayor fuerza que en los años anteriores y la sociedad parisina adopta costumbres inglesas, entre las que destacan el consumo de té, las carreras de caballos y el gusto por las ensoñaciones nocturnas. Como la mayoría de las 
salonnières $^{9}$, madame du Deffand cuenta con invitados ingleses: David Hume llega a la capital en calidad de secretario de la Embajada y a menudo acude al Salón de Saint-Joseph. John Crawford, joven parlamentario británico, también visita a la marquesa en la rue Saint-Dominique y su fantasía, franqueza, incertidumbres y tristezas cautivan a Marie de Vichy. George Selwyn también es un habitual de la sociedad mundana parisina. Este diletante excéntrico había conocido a Horace Walpole en su juventud, y será él quien le remita una carta de presentación para la marquesa. Tras la expulsión de Julie de Lespinasse de su Salón, ese lugar que ha quedado vacante en el corazón de madame du Deffand, se llenará con creces con la entrada en su vida de este caballero inglés.

En 1765, Horace Walpole visita Francia y es presentado a la marquesa, pues ningún extranjero de importancia puede abandonar París sin asistir al Salón de madame du Deffand, si realmente desea conocer la élite de la sociedad mundana. A pesar de que en sus cartas se lamenta de su predisposición a la seriedad y a la melancolía, aquellos que la conocen, al contrario, han dejado una impresión de viveza y alegría como las características más sobresalientes de la marquesa y afirman que incluso en su vejez siempre sorprende por sus dotes e ingenio para la conversación.

Cuando conoce a Walpole, ella tiene sesenta y ocho años y él veinte años menos, pero aun así entre ellos comienza una relación que ha pasado a la historia, pues une para siempre a dos personas que difieren, además de en edad, en nacionalidad y carácter. Walpole, que al principio aunque por poco tiempo desdeñará el Salón, pronto cambia de parecer y participa muy activamente en las conversaciones que se desarrollan en él, cualquiera que sea el tema tratado y pese a sus limitaciones con la lengua francesa. Poco a poco va cautivando a la marquesa y sus lazos de amistad comienzan a estrecharse rápidamente. El desafío literario continuo del inglés impresiona a la marquesa, que continúa padeciendo los vapeurs y, a partir de entonces, la Petite encuentra a son Tuteur.

La irrupción de Walpole en la vida de madame du Deffand provoca una verdadera revolución, pues su espera genérica y siempre desilusionada, así como su ennui, encuentran a un diletante que logra captar toda su atención. Tras numerosas horas conversando sobre sus intereses intelectuales, sus gustos y sus amistades, comienzan a hablar de las intimidades de sus almas; así se percatan, por ejemplo, de que ambos están exasperados por la arrogancia de los filósofos. Walpole es un whig respetuoso de las libertades, pero piensa que los filósofos franceses, en

\footnotetext{
${ }^{9}$ Como señala Marín (2002: 60): "Las damas conocidas habitualmente con el nombre de "salonnières" fueron generalmente contertulias originales y de gran cultura. Actualmente es difícil imaginar la magnitud del influjo ejercido por ellas a lo largo de los siglos en su tarea de espolear, transmitir y equilibrar tanto en el terreno cultural como en el sociológico".
} 
lugar de servir a las libertades se erigen ellos mismos como tribunales dictatoriales y preparan una revolución destructiva. Madame du Deffand, por su parte, es una agnóstica indiferente. Walpole, sin embargo, poco a poco comenzará a tener miedo de su relación afectiva con madame du Deffand: ella, aunque podría ser su madre, lo ama; y ella le recuerda a él, de forma inconsciente, a su madre, a la que tanto amaba.

Con la llegada de 1766, su relación se hace cada vez más estrecha y en abril, al acercarse la fecha de partida de Walpole, llegan a encontrarse todos los días. Walpole, además de acudir a Saint-Joseph, entra en el círculo de amigos de la marquesa, de manera que cenan juntos en casa de Hénault y en las mansiones de la mariscala de Luxembourg, madame Bouffleurs y madame de Forcalquier. El 17 de abril, Walpole regresa a Inglaterra tras un viaje a Francia que ha durado siete meses. El balance de su viaje no puede ser más positivo, gracias al éxito y la confianza en sí mismo que obtiene en París y los placeres de la vida mundana parisina. Desde Chantilly le escribe a la marquesa que, como ocurre con la mayoría de las cartas que le dirige, destruirá a petición suya ${ }^{10}$, pues Walpole teme, ante todo, al ridículo. Como señala Craveri (2005: 251):

correspondencia que se prolonga durante casi cinco [sic.] años y cuenta en su haber con unas mil setecientas cartas, de las que novecientas cincuenta y cinco han llegado a nosotros. De éstas, ochocientas cuarenta son de madame du Deffand, cien -en su mayor parte fragmentos- de Walpole, catorce del secretario Wiart y una de la dama de compañía de la marquesa; setecientas cartas de Walpole fueron destruidas por deseo de su autor.

En sus cartas, la marquesa muestra una sumisión total a las exigencias de su Tuteur, debido a la confianza que tiene en la amistad y en los sentimientos de su amigo. El objetivo fundamental de las cartas es superar la distancia que los separa y evitar a toda costa un alejamiento de Walpole. Madame du Deffand, pese a que le aburre contar, detalla la relación de sus jornadas y los hechos y personajes de la vida mundana. Sin embargo, pese a las reprimendas de Walpole, siempre habla de sí misma de sus reflexiones y de sus sentimientos e intenta ganarse en cada carta a su amigo, con una muestra continua de ingenio y estilo. A principios de septiembre de 1766, Walpole enferma debido a un grave ataque de gota. La marquesa deja al margen entonces todas sus fantasías, que se tornan en aprensiones de carácter maternal. La angustia que padece madame du

\footnotetext{
${ }^{10}$ Walpole se justificará alegando que tiene unos conocimientos muy limitados de francés, lengua en la que ha escrito sus cartas, y que puede ofender por este motivo a quienes se alude en ellas.
} 
Deffand la vuelve autoritaria en sus cartas y exige noticias de su amigo, hace estudiar a su fiel Wiart y planea incluso mandarlo a Inglaterra, pues su impotencia le resulta completamente insoportable. En cualquier caso, las cartas de Walpole alternan severidad con confidencias, y se dirige a ella llamándola bien Madame, bien ma Petite, hecho que desconcierta a la marquesa. Cuando Walpole se recupera y tras dieciséis meses de intenso intercambio epistolar, en julio de 1767 anuncia su regreso a Francia, la alegría desborda a madame du Deffand y en esta ocasión su espera no se ve decepcionada, pues la noche del 23 de agosto el inglés aparece en su Salón. Para ella comienza un período de intensa felicidad pues su amigo ha regresado a París tan solo para visitarla a ella y le dedica casi todo el tiempo de los cuarenta y ocho días que durará su estancia ${ }^{11}$. Aunque la marquesa se muestra en sus cartas en ocasiones como una mujer anciana que espera la llegada de la muerte, la visita de Walpole le dará un nuevo impulso vivificador y olvidará todas sus enfermedades. Walpole, que ahora no se ve asaltado por el miedo a que intercepten sus cartas, se muestra tal y como es, hecho que hace que la marquesa considere que su relación ha mejorado con respecto a lo que se refleja en las cartas. El 8 de octubre de 1767, Horace Walpole se despide de la marquesa para volver a Inglaterra, y ella no puede contener las lágrimas. El día siguiente, ella le escribe (1812: 173):

Que de lâcheté, de faiblesse et de ridicule je vous ai laissé voir! Je m'étais bien promis le contraire; mais, mais... Oubliez tout cela, pardonnez-le-moi, mon tuteur, et ne pensez plus à votre petite que pour vous dire qu'elle est raisonnable, obéissante et, par-dessus tout reconnaissante: que son respect, oui, je dis respect, que sa crainte, mais sa crainte filiale, son tendre, mais sérieux attachement, feront, jusqu'à son dernier moment, le bonheur de sa vie.

Cuando Walpole deja París para volver a su país natal y reanuda su correspondencia, madame du Deffand abandona toda esperanza, aunque sigue esforzándose para contentar a su amigo, evitándole el ennui de los sentimientos y poblando sus cartas de personajes conocidos. Sus ideas fantásticas, promovidas por la ausencia de Walpole, se ven poco a poco paralizadas por la lejanía y el desprecio de su amigo una agonía que se prolongará hasta su muerte.

Sin embargo, madame du Deffand sigue valiéndose de sus amigos y de sus invitados para tratar de olvidarse, al menos de forma momentánea de su ennui. Cada tarde se instala en su Salón, controla la conversación, se entera de las novedades, celebra sus cenas... Evidentemente, para poder aferrarse de tal forma a sus conocidos, a la marquesa le es necesaria una

\footnotetext{
${ }^{11}$ Walpole permanecerá en Francia del 23 de agosto al 8 de octubre de 1767.
} 
gran red de relaciones sociales que ha de mantener y fomentar. Es cierto que el Salón comienza su decadencia tras la despedida de Walpole, mas no se debe tan solo a él, sino al conjunto de situaciones de carácter históricopolítico que suceden en Francia en esos años. El panorama cultural ha cambiado por completo y su centro lo ocupan ahora los centros mundanos de Julie de Lespinasse, del Barón de Holbacj y de los Necker. En cualquier caso, el Salón de Saint-Joseph es una institución de carácter aristocrático que aparece como recuerdo de una época ya pasada. La marquesa comienza a entablar en la década de 1760 una amistad cercana con madame de Choiseul, su grand-maman ${ }^{12}$, a quien conoce desde niña, pues ha sido amiga íntima de sus padres. Como apunta Craveri (2005: 308):

La vanidad de madame du Deffand no puede permanecer insensible a las atenciones de la mujer de uno de los hombres más poderosos de Francia ni mucho menos puede hacerlo su concepción aristocrática del estilo ante la gracia perfecta.

A pesar de las similitudes entre ambas, debido fundamentalmente a sus relaciones sentimentales, son dos mujeres con concepciones de la vida casi completamente opuestas: madame du Deffand se resigna a los cambios en su estado de ánimo y a la vida en general, mientras que madame de Choiseul se enfrenta a la vida con disciplina y un gran sentido ético. Debido a los viajes que ha de hacer la segunda a Versalles, Fontainebleau y Compiègne, junto con sus largas estancias en sus terrenos de Chanteloup, comienza el intercambio epistolar entre ambas, en el que también intervendrá el abate Barthélemy ${ }^{13}$. Walpole, por su parte, anuncia una nueva visita a madame du Deffand de nuevo durante el verano de 1769 y llega a París el 18 de agosto. Le dedica todas sus veladas, cenan juntos en París, pasean por los nuevos bulevares de la capital y en la carroza de madame du Deffand. Este viaje se prolongará hasta el 5 de octubre.

Madame du Deffand, pese a su nueva relación de amistad con la duquesa de Choiseul y su agitada correspondencia con Walpole, está

\footnotetext{
${ }^{12}$ Munat (2003: 218) afirma al respecto: "Dans toute la correspondance échangée entre Mme du Deffand et Louis-Honirne, le duc et la duchesse de Choisseul sont invariablement le 'grandpapa' et la 'grand-maman', tandis que Marie de Vichy devient la petite fille. L'inversion n'est qu'un jeu mondain quelque peu maniéré".

13 Jean-Jacques Barthélemy (1716-1795): escritor y numismático. Nace en Cassis, en la Provenza francesa, y comienza sus estudios con los jesuitas. Cuando entra en el seminario, con la intención de consagrar su vida a la vida religiosa, comienza a interesarse por las lenguas orientales, así como por la numismática. Barthélemy escribirá un gran número de ensayos sobre las lenguas de Oriente y arqueología, escritos para su lectura en la "Académie des inscriptions et belles-lettres". Entre sus obras destacan Les amours de Caryte et de Polydore, una novela sobre las costumbres antiguas, y sus Mémoires. Mme de Choiseul lo llama le grand abbé.
} 
preocupada por la salud de Hénault, que fallece el 24 de noviembre de 1770 , por lo que la marquesa recibe numerosas condolencias por parte de sus amigos. En el testamento del presidente ella aparece en première ligne y le son destinadas 6.000 libras.

El 24 de diciembre de 1770, tras la muerte de madame de Pompadour y el ascenso de la condesa du Barry, amante de Luis XV, M. de Choiseul recibe una lettre de cachet mediante la cual ha de renunciar a su cargo como Secretario de Estado y abandonar su residencia en un plazo máximo de veinticuatro horas y marcharse al exilio a sus terrenos de Chanteloup. La marquesa considera este suceso como una nueva despedida, en este caso de madame de Choiseul, de manera que esta correspondencia se entrecruza con la que la marquesa mantiene con Walpole. Como muestra de su amistad, e ignorando las órdenes que le da el inglés, en 1772 madame du Deffand se decide, tras numerosas dudas debido a su delicado estado de salud y el largo viaje, a pasar seis semanas en Chanteloup, con los Choiseul, que suponen una posibilidad de amistad con la que hacer frente a los desprecios de Walpole. Cuando la marquesa regresa a París, encuentra una carta en la que Walpole le reprocha su viaje; ha preferido remitirle su carta a Saint-Joseph para evitar que haya testigos así como la mediación de la duquesa de Chosieul, pues continúa su miedo a que las cartas sean interceptadas.

La relación con Walpole supone que la marquesa relegue a un segundo plano su correspondencia con Voltaire, aunque nunca la interrumpirá, Craveri (2005: 323) afirma:

\begin{abstract}
Madame du Deffand quiere cobijarse bajo el prestigio de Voltaire, y Voltaire servirse de la red de relaciones de madame du Deffand para reforzarlo, así como la marquesa necesita escribir a Walpole para dar un sentido a su vida y Walpole las cartas de ella para vivir indirectamente una situación mundana; y, en tiempos, ¿no escribía d'Alembert a madame du Deffand para dar un eco a su monólogo intelectual y la marquesa a él para reflejarse en la inteligencia de su protegido?
\end{abstract}

También seguirá su amistad con Pont-de-Veyle que, pese a su egoísmo e indiferencia naturales, ayuda a Marie de Vichy a encontrar la tranquilidad que busca ahora en su vida real y mundana. Sin embargo, cuando él muere en 1774, se verá muy afectada al perder a otro de sus mayores apoyos de siempre. Bajo las "luces" de la escena social, la marquesa prefiere la calma de la indiferencia amistosa, de la que destaca el placer por la conversación. Es, sin duda, la mejor manera de afrontar sus largas noches de insomnio, derivadas de su gran actividad intelectual así como de los vapeurs que la angustian. Las tinieblas se ciernen sobre su 
vida, procedentes de su absoluta desesperación. Esta especie de enfermedad perpetua la lleva a tener una leve, pero constante, sensación de angustia y tristeza. Por este motivo se refugia en el gusto del arte escrito y oral, así como en la ligera alegría de la frivolidad, pues disipan provisionalmente esas tinieblas y aportan tranquilidad a su vida.

Dos años más tarde, el 22 de mayo de 1776, muere Julie de Lespinasse, de modo que paulatinamente la muerte acecha cada vez más cerca a madame du Deffand. En septiembre de 1775 ve por última vez a Walpole, puesto que tres años después Francia entrará de nuevo en conflicto con Inglaterra. Su correspondencia no se ve interrumpida, pero al inglés le será imposible volver a cruzar el estrecho para encontrarse con su amiga. Ya en 1771 le ha pedido a Walpole autorización para nombrarlo heredero de sus cartas. Ella es consciente del gran atractivo que supone para un coleccionista e historiador como Walpole, pero en cierto sentido la marquesa también es consciente del valor de sus cartas, especialmente sus retratos y su correspondencia con Voltaire. Una vez obtiene el consentimiento de Walpole, redactará su testamento el 13 de febrero de ese mismo año.

El 10 de febrero de 1778 Voltaire vuelve a París y un día después le entrega a Wiart, que ha ido a pedir noticias suyas a petición de la marquesa (1812: 11s), la siguiente nota: "J'arrive mort, et je ne veux ressusciter que pour me jeter aux genoux de madame la marquise du Deffand". El 14 de febrero se encontrarán de forma emotiva y la marquesa ha de reconocer su alegría por ver a su viejo amigo. Sin embargo, poco después, en mayo Voltaire muere en París ${ }^{14}$ sin volver a ver a Marie de Vichy.

Las enfermedades de madame du Deffand van agravando su delicada salud $y$, atemorizada por una incipiente sordera y otros problemas, consigue que el hijo de madame de Aulan, hermana de la marquesa, se traslade con su esposa a unos aposentos independientes en el convento a finales de 1778. Wiart, con su esposa y varios criados le aseguran una vida material confortable y madame du Deffand también cuenta con un lector para asistirle en sus horas de insomnio. En cualquier caso, se siguen celebrando sus dos cenas semanales (los miércoles y los viernes) que siguen atrayendo a numerosos comensales y no hay extranjeros ilustres que abandonen París sin haberla visitado en Saint-Joseph.

El 22 de agosto de 1780, madame du Deffand escribe la que será su carta de despedida a Walpole, acabando así de forma simbólica la unión con su Tuteur. Los invitados siguen llegando a su Salón pero poco a poco la

${ }^{14}$ El cadáver del filósofo, sin embargo, es cargado en una carroza debido ya que no permiten darle sepultura en París. 
marquesa se va sumiendo en un letargo y morirá el 23 de septiembre de 1780.

2. TRADUCCIÓN AL ESPAÑOL DEL RETRATO DE MADAME DU DEFFAND ESCRITO POR DE FOS

A tenor de lo expuesto anteriormente, hemos podido apreciar el carácter de la marquesa Du Deffand. No obstante, junto con las notas biográficas referidas a lo largo del apartado anterior resulta de gran interés para comprender la personalidad de Marie de Vichy mencionar uno de los retratos en verso, habituales en el siglo XVIII, concretamente el que le escribe con gran dureza e ironía De Fos ${ }^{15}$, que recogemos a continuación con su correspondiente traducción, realizada por vez primera al español y que consideramos de gran interés para poder tener una cosmovisión de esta "salonnière" y epistológrafa tan destacada e influyente del siglo XVIII francés.

\footnotetext{
${ }^{15}$ De Fos, L. (1868). "Septième Portrait. La marquise Du Deffant (Marie de Vichy). 1697-1780". En: De Fos, L. Douze portraits de femmes dessinés à la plume. Riom: Imprimerie de G. Leboyer, pp. 17-20.
} 


\section{LA MARQUISE DU DEFFANT (MARIE DE VICHY)}

(1697-1780)

Madame du Deffant qui, par plus d'un bon mot,

Se fit de renommée un assez brillant lot,

Et qui n'épargnait point au besoin l'épigramme,

Elle dont l'esprit fort se disait son surpris

De voir si peu d'élus aux célestes lambris,

"Tant pour l'homme elle avait, sans excepter la femme,

" Un fond très profond de mépris, "

Et qui, de Montesquieu jugeant le grand ouvrage,

L'appelait finement de l'esprit sur les lois,

Ecoutait, dit-on, une fois,

Deux hommes discourir d'un étrange voyage.

Ils parlaient du chemin qu'avait fait saint Denis,

D'après une légende ou dîct du moyen-âge,

En portant dans ses bras sa tête au saint Parvis,

Tout en la baisant sur la route.

L'un disait quatre pas, l'autre cent - À quoi bon,

Fit-elle, calculer ? en telle occasion,

"Cest toujours seulement le premier pas qui coûte. »

Elle eut beaucoup d'esprit sans doute,

Mais du cœur, non ; le sien ne fit jamais tic-tac,

Ou du moins il était tout dans son estomac;

Ce qu'elle aimait le mieux, c'était la bonne chère,

Elle a pu se montrer sur d'autres points sévère,

Froide du moins ; jamais sur l'article repas.

C'est elle qui disait: "Les soupers sont, en somme,

"L'une des quatre fins de l'homme;

"Des trois autres, ma foi, je ne me souviens pas. "

Mais voici bien plus fort : Le jour où Pont-de-Veyle,

Son ami de trente ans et presque son époux,

Rendit à Dieu son âme frêle,

Elle fut, pour souper, exacte au rendez-vous. 


\section{LA MARQUESA DU DEFFAND (MARIE DE VICHY)}

(1697-1780)

Madame du Deffand, por más de una agudeza, logró reputación con exceso y largueza, tampoco escatimaba si acaso el epigrama; ella, cuyo ateísmo decía no sorprenderse viendo en palcos del cielo a tan pocos elegidos: tenía en cuanto al hombre, como hacia la mujer, un fondo muy profundo de desprecio; cuando de Montesquieu juzgaba su gran obra, con finura tildábala "de ingenio, antes que leyes": se dice que una vez oía a dos hombres disertando acerca de un extraño viaje. Hablaban del camino que había hecho san Denís según una leyenda o poema medieval, llevando entre sus brazos su testa al santo atrio, mientras la iba besando al hacer el camino.

Decía uno cuatro pasos, decía el otro ciento. ¿Para qué calcular? En una ocasión tal "siempre es el primer paso el único que cuesta". Atesoró ella mucho ingenio, no hay duda, mas corazón no tuvo: nunca palpitó el suyo, o al menos se situaba donde estaba el estómago; lo que más le gustaba era la buena mesa: si en otros puntos pudo mostrarse más severa, o al menos fría, nunca en la cuestión comida. Ella era quien decía: "Las cenas son, en suma, uno de esos cuatro fines que tiene el hombre; y de los otros tres yo no me acuerdo nunca". Mas, he aquí algo más gordo: el día en que Pont-de-Veyle, su amigo hace treinta años, y casi su marido, rindió a Dios su alma débil, ella asistió a la cita de la cena a hora exacta. 
Et, comme on lui parlait d'un ami si fidèle

Et des pleurs qui, sans doute, inondèrent ses yeux

A cette fatale nouvelle :

" $A$ six heures du soir il est mort, reprit-elle,

"Vous ne me verriez pas sans cela dans ces lieux. "

Et là-dessus, de peur de blâme,

Rompant le fond de l'entretien,

Elle but et mangea fort bien...

Hélas ! ventre affamé, je le vois, n'a point d'âme.

Oui, son cœur était sec... et si, dans sa jeunesse,

Femme d'un laid richard, et du régent maîtresse,

A profit doublement elle mit sa beauté,

Elle n'attendit pas tout-à-fait la vieillesse

Pour tirer bon parti d'un esprit redouté,

Et se faire à Paris une autre royauté ;

Car tout était calcul en ce cœur égoïste.

Ennuyée et moqueuse, étincelante et triste,

Pour se désennuyer elle ouvrit son salon

A tous les beaux esprits de France et de Navarre:

Cercle très-bigarré dont elle était le phare,

Concert dont elle était le premier violon.

Là, régnant par l'esprit et par son chef d'office,

Crainte pour ses bontés, crainte pour sa malice,

De son siècle elle fut l'oracle et le Solon.

Là se réunissaient, comme dans un lieu,

Montesquieu, d'Alembert, Choiseul et d'Aiguillon,

Hume, Gibbon, Walpole, ... et Voltaire lui-même,

Que, tout en le flattant, elle exécrait, dit-on,

Et qui la détestait en lui disant : je t'aime.

Bref, c'est là qu'on prenait son extrait de baptême,

Sa lettre de crédit, son brevet de bon ton ;

Et depuis le haut dignitaire

Jusqu'à l'abbé poupin, ou poupart ou poupon,

Sans l'aimer, subissant son joug involontaire,

Tous venaient courtiser ce Mécène en jupon. 
$\mathrm{Y}$, como preguntáranle por amigo tan fiel, y sin duda sus ojos se inundaron de lágrimas ante esta fatal nueva expresó:

a las seis de la tarde falleció,

a mí no me veréis frecuentar esos sitios.

Y sobre ese asunto, por miedo al reproche, cortando el fondo de la charla,

ella bebió y comió muy bien...

$¡ A y !$, un vientre hambriento, lo veo que no tiene alma.

Tenía el corazón seco..., y si, en su juventud,

mujer de un feo ricacho y amante del regente,

en la doble ganancia colocó su belleza,

no esperó que llegara la vejez a su tiempo

para sacar partido de un ingenio temido,

y en París conseguir una especial realeza;

pues todo cálculo era en este alma egoísta.

Aburrida y burlona, chispeante y melancólica,

para salir del tedio ella abrió su salón

a todo hermoso ingenio de Francia y de Navarra:

círculo abigarrado del cual ella era faro,

concierto del que ella era el primer violín.

Reinando por ingenio y por su cocinero,

por su bondad temida, como por su malicia, de su siglo ella fue oráculo y Solón.

Allí se reunían, igual que en un combate

Montesquieu, d'Alembert, Choiseul, d'Aiguillon,

Hume, Gibbon, Walpole..., y hasta el propio Voltaire, al que, mientras loaba, cuentan que lo execraba,

y quien la detestaba al decirle: te quiero.

Allí uno se sacaba partida de bautismo,

de crédito su carta, su diploma de estilo;

y desde el alto dignatario

al abad rubicundo, cangrejo o angelote,

sin amarla, sufrían su yugo involuntario,

a cortejar allí iban al mecenas en sayas. 
Frondeuse, et d'un sceptique ayant la froide étoffe, Elle avait en mépris pourtant tout philosophe :

Et quelques-uns disant au commun intérêt

Avoir des préjugés immolé la forêt :

Je ne m'étonne pas, Messieurs, répondit-elle,

Si vous nous débitez alors tant de fagots...

A leurs enseignements quoique toujours rebelle,

Elle n'en fut pas plus à son culte fidèle,

Et des prêtres traitant les discours de ragots,

Quand la mort s'abattit sur ses paupières closes,

Elle dit au curé : Fussiez-vous Salomon,

Faites-moi grâce de trois choses:

L'abbé, ni questions, ni raisons, ni sermon.

Son corps donc au séjour de l'éternelle flamme

Dut aller après son trépas;

Son esprit est resté sur la terre... et son âme...

Dieu n'en a pu rien faire... Elle n'en avait pas. 
Conspiradora y escéptica, siendo de fría madera, sentía un gran desprecio por todos los filósofos, y a algunos que apelando al común interés sin prejuicio ninguno inmolaban los bosques, respondía ella: señores, yo no me asombro de eso, si nos suministráis tantos haces de leña...

Ante sus enseñanzas, aunque siempre rebelde, ella no les fue nunca a su culto leal, ni a los padres que hablaban de chismes en sermones; cuando llegó la muerte a sus cerrados ojos, ella le dijo al cura: si fueseis Salomón concededme tres cosas:

nada de interpelarme, entenderme ni sermonearme.

Su cuerpo a la estancia de la llama inmortal debió ir tras su muerte;

su espíritu quedó en tierra..., y su alma...

Dios no pudo hacer nada, ya que alma no tenía. 


\begin{abstract}
CONCLUSIÓN
Si comparamos el Salón de madame du Deffand con los Salones franceses esencialmente sociales, este está más marcado que los demás por la aceptación de determinadas ideas filosóficas (pese al rechazo que siente la Marquesa por les philosophes) y filantrópicas derivadas del estado de inquietud intelectual en los años previos a la Revolución Francesa. Su Salón abarca todas las ramas del pensamiento, aunque nunca llegarán a predominar completamente los aspectos políticos, filosóficos ni literarios en sí mismos. El ingenio, la brillantez y las "armas" intelectuales se dan cita en el Salón de Marie de Vichy. Poco a poco, la introspección, el análisis de conocer las causas y las condiciones de lo que sucede, e incluso de la crítica, gana terreno a la conversación estrictamente jovial y placentera. Madame du Deffand es un vivo ejemplo del efecto que produce esta situación en las personas más destacadas de la época, pues representa el apasionado deseo de descubrir la verdad a toda costa, así se lo hace ver a Voltaire en numerosas cartas, y de quitarle todas las máscaras, las farsas y todo lo prescindible.
\end{abstract}

\title{
REFERENCIAS BIBLIOGRÁFICAS
}

CoBos, Laura. Madame du Deffand: Frivolidad y agonía (Correspondencia). Introducción de Fernando Savater. México: Fondo de Cultura Económica, 1988.

ClÉMENT, Jean-Marie-Bernard y Joseph de LA PORTE. Anecdotes dramatiques, vol. III, Paris, 1775.

Craveri, Benedetta. Madame du Deffand y su mundo. Traducción de Esther Benítez. Madrid: Siruela, 2005.

DE FOS, L. "Septième Portrait. La marquise Du Deffant (Marie de Vichy). 1697-1780". En: De Fos, L. Douze portraits de femmes dessinés à la plume. Riom: Imprimerie de G. Leboyer, 1868, pp. 17-20.

GONCOURT, Edmont y Jules GONCOURT. L'Art du dix huitième siècle par Edmond et Jules de Goncourt, t. II, Paris, 1874.

Henault, Charles-Jean-François. Mémoires du Président Hénault de I'Académie française, écrits par lui-même, recueillis et mis en ordre par son arriere-neveu M. le baron de Vigan. Paris: E. Dentu, 1855. , Mémoires du Président Hénault. Genève: Slatkine, 1971.

LESCURE. Correspondance complète de la marquise du Deffand avec ses amis: le président Hénault, Montesquieu, d'Alembert, Voltaire, Horace Walpole, classée dans l'ordre chronologique et sans suppressions, augmentée des lettres inédites au chevalier de L'Isle, précédée d'une histoire de sa vie, de son salon, de ses amis, suivie de ses œuvres diverses et éclairée de nombreuses notes par $M$. de Lescure. 
Ouvrage orné de deux portraits gravés par Adrien Nargeot et plusieurs facsimilés, 2 vols. Paris, 1865.

LEWIS, W.S. "Portrait de Mme la M[arquise] du D[effand] fait par elle-même en 1728". En: Lewis, W. S. Horace Walpole's Correspondence with Madame du Deffand and Wiart, v. IV, New Haven and London: W.S. Lewis \& W.H. Smith, 1939.

MARÍN MARTí, Amalia. El Salón como universo social en la Francia del siglo XVII. Córdoba: Servicio de Publicaciones de la Universidad, 2002.

MURAT, Inès. Madame Du Deffand, 1696-1780: La lettre et l'esprit. Paris: Perrin, 2003.

VICHY-ChAMPROND, Marie de, Marquise du Deffand. Letters of the Marquise du Deffand to the Hon. Horace Walpole, afterwards Earl of Orford, From the Year 1766 to the Year 1780, to which are added Letters of Madame du Deffand to Voltaire, From the Year 1759 to the Year 1775. Published from the originals at Strawberry-Hill. 4 vols. London: Longman, Hurst, Rees, and Orme, 1810.

, Lettres de la Marquise du Deffand à Horace Walpole, depuis Comte d'Orford, écrites dans les années 1766 à 1780; auxquelles sont jointes des Lettres de Madame du Deffand à Voltaire, écrites dans les années 1759 à 1775. Publiées d'après les originaux déposés à Strawberry Hill. 4 tomes. Paris: Chez Treuttel et Würtz, 1812. , Lettres à Voltaire. Paris: Rivages, 1994. 